\title{
La mediación y el ciudadano: responsabilidad de las decisiones en situaciones conflictivas
}

\author{
CONSUELO ARES DE GIORDANO \\ Universidad Nacional de Cuyo (Mendoza. República Argentina)
}

\section{LA CRISIS ACTUAL}

EN MEDIO DE LA PROFUNDA CRISIS ARGENTINA, está cuestionada la legitimidad del sistema político, la representatividad, las formas de participación, y los modos de la ciudadanía. A 20 años del retorno de la democracia seguimos inmersos en una crisis tan profunda que bien puede atribuírsela al propio modelo representativo, ya que así lo manifiestan también la mayoría de las democracias actuales. La repetida consigna «ique se vayan todos!», de diciembre de 2001 , expresó un hartazgo de la ciudadanía argentina por los políticos, quienes perdieron toda credibilidad. Sin embargo, mucho se ha criticado porque esa protesta multitudinaria no se canalizó en un mayor compromiso de todos por el interés común, ni en un ejercicio más responsable de los deberes ciudadanos. Este año electoral no despierta gran interés, ni mucho menos esperanza, de encontrar las soluciones adecuadas a tantos problemas pendientes. En medio de ese descrédito de la política y de los políticos, a pesar de la cantidad de candidatos, no hay verdaderas opciones. Se advierte cierta irracionalidad en los procedimientos públicos de decisión.

El fracaso de los políticos, incapaces de conciliar las exigencias de la sociedad con los procedimientos de participación política, puede explicar parcialmente ese descreimiento y apatía. Pero resulta insuficiente. ¿No será que no hemos sido suficientemente creativos y responsables al momento de reformular y reorganizar nuestras instituciones sociales y políticas? Una reconciliación efectiva de la democracia con la racionalidad social, y no sólo económica, requiere la promoción de aquellas instituciones que fomentan la participación y la cooperación social como comportamiento mayoritario para 
resolver los conflictos. Sólo así se asumirá plenamente la condición de ciudadanos con intereses comunes. Entonces el interrogante girará sobre las condiciones que favorecen esa democracia renovada, y sobre las instituciones que ella requiere. Proponemos una transformación institucional y no solamente conceptual de la democracia como vía para asegurar la estabilidad política y la paz social.

En ese marco de cambio institucional advertimos, en primer lugar, una carencia de formación democrática de los ciudadanos tal que les permita esa participación efectiva requerida. Ante esta situación, explicable parcialmente por nuestra histórica alternancia entre gobiernos democráticos y golpistas, a la clase política no parece interesarle mucho la educación cívico política. Pero tampoco la ciudadanía la reclama enérgicamente. Para rescatar a los ciudadanos, tanto a los que han desertado como a los que han sido excluidos, hay que promocionar el modelo participativo en las distintas instancias de la vida social, y el compromiso en resolver los conflictos que sin duda conlleva su aplicación. Después de todo, no hay democracia sin demócratas y $\sin$ conflictividad social. ${ }^{1}$

\section{EN BUSCA DE SOLUCIONES}

El hombre históricamente ha apelado a diversos mecanismos para buscar cómo solucionar sus controversias. Es así como antiguamente recurrió a la magia, a la venganza y al restablecimiento de la paz. Esta última estrategia desembocó en el procedimiento judicial formal. El Derecho moderno se ha caracterizado, entre otros aspectos, por la separación entre la autoridad parental y la política, por la centralización del poder y por el establecimiento de un proceso institucionalizado para resolver conflictos. Hablamos del Derecho según se lo entiende en la actualidad, que decide en base a la justicia y no a las relaciones de fuerza.

Los procedimientos judiciales tienden a una racionalidad completa, ligada a criterios institucionales independientes, externos, debidamente anticipados y universales. Determinados asuntos necesitan de una regulación jurídica, de decisiones adoptadas según esos criterios. Sobre todo cuando se trata de conflictos de cierta relevancia social, que exigen una respuesta unívoca, a plazo fijo y vinculante para todos. Las normas jurídicas son las que mejor lo resuelven. Como dice Habermas, el Derecho es una compensación de las debilidades de una moral autónoma ${ }^{2}$. Aún cuando, en la realidad, su aplicación no refleja tanta precisión. En el desarrollo del Derecho hay una distancia real entre el pretendido modelo de un sistema jurídico unitario, uniforme y universal,

1 Cf. J. Rubio Carracedo, Educación moral, postmodernidad y democracia, pp. 198 ss.

2 J. Habermas, Conciencia moral y acción comunicativa, p. 206. 
y la multiplicidad de prácticas sociales locales, cotidianas, que están bastante distantes de aquél. Esa distancia no es más que la tensión entre lo formal y lo informal, entre lo oficial y lo popular, en última instancia entre la facticidad y la validez, como sostiene el filósofo alemán.

La judicialización de los conflictos más variados llevó a suponer que los Tribunales resultaban el ámbito apropiado para resolver cualquier problema, ya fuera éste no solamente jurídico, sino también económico, político, social o cultural. Quizás se pretendió que el Derecho cubriera el vacío dejado por una ética social, de la que hemos carecido y todavía carecemos en nuestra sociedad actual, tan posmoderna y globalizada. Sin embargo, ello desbordó las posibilidades del Poder Judicial, porque intrínseca y técnicamente era imposible que pudiera dar soluciones efectivas a problemas no jurídicos, o mejor no necesariamente judicializables.

El proceso judicial formalizado fue el eje sobre el que giró la protección de los derechos individuales. Si bien se ha apelado a la vía judicial adversarial para resolver conflictos personales y grupales, ya concluido el proceso, algunas veces la sentencia no resuelve las disputas en su sentido real, y otras no deja satisfecha a ninguna de las partes, ni siquiera a la ganadora. Estas prácticas judiciales se muestran como juegos de suma cero: lo que yo gano, tu pierdes; y lo que yo pierdo, tú ganas. Pero, parece que el conflicto judicializado no siempre es más rentable que la conciliación. Por eso han comenzado a implementarse en nuestro país procedimientos de solución de disputas que se consideran como «extra-judiciales». En ellos, los mismos afectados, con asistencia y asesoramiento especializado, intervienen directamente en la composición del conflicto y en la posible solución. Nos referimos a procedimientos alternativos como la mediación, el arbitraje y la negociación. Superadores de las lógicas de confrontación que terminan por hacer de los afectados «rehenes» de sus propios conflictos, proponen otras formas de gestionarlos a través del diálogo, de la participación comprometida, del compromiso en la búsqueda de una solución, y de la responsabilidad frente a ella. Orientados más hacia la comunicación que a la confrontación, se apoyan en una concepción de relaciones sociales solidarias y comprometidas.

Estas llamadas «vías alternativas de resolución de conflictos» pueden encuadrarse dentro del «paradigma procedimental» sostenido por Habermas ${ }^{3}$, según el cual, los sujetos jurídicos, destinatarios y también autores del Derecho, en su condición de ciudadanos, pueden entenderse entre sí sobre cuáles son sus problemas y cómo deben ser resueltos. Dentro de este paradigma, al ciudadano se lo considera como participante responsable en la toma de decisiones. Estas se explican por el principio del discurso, que considera válidas

3 J. Habermas, Facticidad y validez, pp. 260 ss. 
«todas aquellas normas a las que, todos los que puedan verse afectados por ellas, pudiesen prestar su asentimiento, como participantes en discursos racionales» 4 . Esa participación procedimental cooperativa, en el proceso de realización o concreción del Derecho, es justamente lo que permite relacionar el sistema jurídico positivo -ahora revaluado colectivamente-con el rol activo de ciudadano. Para ello será necesario capacitarlos, a fin de que puedan resolver sus problemas por su cuenta, conforme a mecanismos efectivos de participación. Ello implicaría una profunda reforma del sistema judicial.

Somos conscientes de que, entre las diversas propuestas de reforma al sistema judicial, las que apuntan a la modificación de los procedimientos son las más frecuentes, las que generan menos resistencia y las que pueden concretarse con mayor facilidad. Pero hablar de un paradigma procedimental no implica cambiar, en términos de eficiencia, la operatoria cotidiana del Poder Judicial a través de nuevos códigos, sino que apunta a un salto cualitativo, con una visión más amplia del sistema de justicia, del cual el procedimiento legal es sólo un emergente. Implica modificar tanto el aspecto funcional como estructural, en vistas de reformular la administración de justicia.

Coincidimos con un destacado jurista argentino, el Dr. J. C. Cueto Rúa, en la aparición de signos de cambio sustancial en los procedimientos de resolución de conflictos, en los que el juez ya no tiene una posición central dominante y excluyente: «Hace ya varias décadas comenzaron a ganar difusión, en Inglaterra y Estados Unidos, procedimientos de solución de disputas al margen de la intervención del juez del Estado. Las propias partes interesadas en la solución de las controversias, con asistencia y asesoramiento letrados, han comenzado a adoptar medidas de intervención directa en la composición de las controversias y en la búsqueda de soluciones transaccionales que pongan fin a los litigios. En los Estados Unidos más del $80 \%$ de los juicios llevados al conocimiento de los jueces estatales para su decisión son transados o arreglados por las propias partes litigantes. En Inglaterra el porcentaje es aún mayor, oscila alrededor del $90 \%$ de los casos litigiosos sometidos al conocimiento de los jueces... Los jueces argentinos no utilizan los instrumentos puestos a su disposición por los legisladores, para promover activamente las transacciones, las mediaciones y los arbitrajes. Prefieren una actitud pasiva; neutral, expectante. Los valiosos instrumentos del art. 36 del Código Procesal para hacer justicia a las partes, son poco utilizados. Ello priva a la sociedad argentina de un poderoso instrumento para hacer justicia» 5 .

En ese contexto de cambio deberían insertarse estos métodos alternativos, como la mediación, porque implican un cambio cualitativo del procedimiento

4 Ibid., p. 171.

5 El proceso de masificación y la resolución judicial de los conflictos, p. 1. 
judicial, en tanto son vías más flexibles y abiertas para llegar a una solución. No hablamos de un procedimentalismo a ultranza, que gire sobre la habilidad técnica, o en última instancia sobre la destreza de los expertos, sino de una necesaria revisión de los procedimientos por todos aceptados para la práctica del Derecho, cuyas limitaciones o vicios suelen ocultarse en la formalidad, o en la misma factualidad y que, una vez reconocidos, deberían ser enmendados.

\section{LA MEDIACIÓN}

Entre esas vías alternativas de resolución de conflictos nos detendremos en la mediación, "proceso en el que un tercero neutral ayuda a las partes en conflicto a lograr su propio acuerdo para resolver la disputa». Orientada más hacia la comunicación que a la confrontación, se apoya en una concepción de relaciones sociales solidarias y comprometidas. Apunta a resolver las llamadas disputas en justicia, que es cuando personas en desacuerdo apelan a principios de justificación diferentes para sostener argumentadamente sus puntos de vista $\mathrm{y}$, si cabe, buscar los modos de un acuerdo válido. Protege las relaciones interpersonales, convoca a las partes involucradas en el conflicto a encontrarse y conversar para facilitar una posible solución, favoreciendo el diálogo y la escucha profunda de los protagonistas. Todo esto se logra con menores costos emocionales y económicos y en un tiempo más breve que en el proceso adversarial tradicional.

En nuestra provincia, Mendoza, la mediación viene aplicándose con regularidad para la resolución de conflictos familiares desde 1998, y con un ritmo intenso y creciente. En el Cuerpo de Mediadores de los Juzgados de Familia en Mendoza, desde su creación hasta fines del 2002, se han atendido casi 20.000 casos, con un $40 \%$ de acuerdos firmados. También han comenzado a funcionar Programas de mediación municipal y vecinal, implementados en algunos departamentos de la provincia. Dado que existe una cierta experiencia acumulada en estos itinerarios alternativos al proceso formalizado, nos proponemos una mirada crítica ante posibles perspectivas de consolidación de este mecanismo estatal -hasta ahora- para gestionar y resolver demandas sociales y particulares.

Desde el ámbito jurídico se considera la mediación como una vía alternativa de resolución de conflictos. Nosotros le damos a «alternativo» otro sentido distinto al que hemos encontrado en la bibliografía especializada -que lo considera así por su aparente enfrentamiento con el procedimiento judicial. La tomamos en cuanto respeto al otro -alter-en su calidad de prójimo, no de adversario. «El otro» es aquél con quien estamos dispuestos a contrastar nuestra postura, a admitir la posibilidad de crítica, y a plantear un diálogo comprometido en busca de un consenso posible. Ello no implica un ingenuo acuerdo universal, ni manipulaciones más o menos disimuladas, ni ocultamiento de las 
contradicciones, sino la incorporación efectiva, tanto a nivel de discurso como de prácticas concretas, de las reales demandas de todos los protagonistas involucrados en el conflicto. Sólo así, cualquiera sea el resultado en la práctica, será respetado por ellos mismos. Esto supone una interacción que reconcilie, no anule, intereses opuestos. El ansia de eliminar diferencias no genera consenso. Este sólo se produce si hay una «mirada» que custodia al otro en su distinción, una atención que lo comprende sobre la base del reconocimiento de su propia distancia. Por eso podemos hablar de una «armonía en tensión»y no de un consenso ingenuo.

La resolución del conflicto no es ajena a las partes, sino que proviene de ellas, de su capacidad de análisis y de decisión. Si el mediador maneja esta práctica adecuadamente y logra involucrar a las partes, se puede lograr una profunda transformación de éstas, lo que a veces -no siempre-se exterioriza en un acuerdo formalizado. Habría que distinguir entre un «compromiso» como acuerdo entre dos mundos de acción, basado en la defensa del bien común superior reconocido por las partes en disputa, al que se llega a través de una deliberación, y un «arreglo» que es una transacción contingente, negociada, sin bien común superior, basada en el interés y la convivencia recíproca de los partícipes: «tú haces esto porque me conviene, yo hago esto que te conviene». En la mediación se priorizan los procesos decisionales deliberativos por encima de la mera negociación.

Cuando dos partes dialogan existen, ciertas pretensiones de validez, como dice Habermas. En primer lugar, el sujeto hablante quiere ser comprendido o entendido. Pero la inteligibilidad de su mensaje no se da espontáneamente, hay que esmerarse en lograrla, a veces con resultados infructuosos. ¿Acaso no existe la posibilidad de la confusión comunicativa, producto de múltiples factores, como los emocionales, o los culturales, por mencionar los más inmediatos? También ese sujeto pretende que su mensaje sea considerado sincero por quienes lo escuchan. Pero la veracidad choca con la cultura de la desconfianza, a la que estamos muy habituados por nuestra historia social y personal. Tendemos a pensar muchas veces en qué es lo que esconde el otro detrás de sus palabras. Ese frecuente doble mensaje. Además el que habla parte de una suposición: que su postura en el diálogo es la correcta, se ajusta a una norma de convivencia aceptada, y pretende entonces que así sea tomada y respetada. Sin embargo, no hemos sido educados en el respeto a la norma, sino en el descuido de las mismas. Por eso nos tiene sin cuidado si el otro tiene o no razón. Todas estas pretensiones mencionadas juegan como supuestos que posibilitan el diálogo, y a partir de ellas buscaremos el consenso ${ }^{6}$.

6 Cf. La necesidad de revisión de la izquierda, p. 188. 
Ahora bien, esas pretensiones dialogales surgen en determinados sujetos cuya historia personal ha desembocado en ciertos conflictos. Pretensiones, historia personal y conflicto son tres dimensiones interdependientes que deben ser tenidas en cuenta en la mesa de mediación. Las dos primeras han sido parcialmente descuidadas en el desarrollo de esta práctica, al menos hasta el momento. Focalizar la atención en ellas requerirá disponer una preparación para el encuentro inicial, y también una preocupación por conocer el posible perfil de los mediados por parte del mediador, más allá de supuestas generalizaciones que permitirían anticiparlo o ignorarlo.

Si se toman en cuenta las pretensiones de los mediados, deberá cuidarse que tengan efectivas posibilidades de expresarlas, allanando ese camino ante cualquier barrera que pudiera surgir, sea ésta emocional, cultural, social, religiosa, etc. Si importa realmente la historia personal de esos sujetos habrá que atender muy bien a su contexto vital, conocer sus limitaciones como así también sus fortalezas. Y asimismo el posible efecto de un supuesto acuerdo, cómo impactará en su vida cotidiana en caso de que se arribe al mismo. Desde estos dos ejes entrecruzados, recién entonces se podrá desmenuzar la naturaleza del conflicto y la dinámica que puede generar su abordaje.

Sólo en la medida en que se rescate el papel central que juegan los mediados se harán efectivos los supuestos de participación y compromiso en la búsqueda de solución por parte de ellos mismos, que supone la mediación. De lo contrario, se limita a la consideración de la mejor manera de conducir el proceso, en un plano predominantemente formal, sin incluir el cuidado o atención por el posible resultado posterior, que sin duda se extiende mucho más allá del acuerdo materializado.

En ese sentido, la mediación debería ser vista como un proceso de cambio, y no como un acontecimiento singular. $\mathrm{Y}$ ese cambio se da tanto a nivel individual como social. De lo contrario, hacemos un corte arbitrario entre los diversos aspectos de la vida personal y social, e introducimos allí una práctica totalmente ajena al entorno de cada uno, pasada la cual, todo vuelve a la situación previa. Por eso, el resultado a que se llega en la mediación no puede limitarse al acuerdo, o al menos éste debería ser leído con un matiz de provisoriedad. O mejor aún, como de textura abierta, que podrá ser modificado constantemente aún cuando se cumpla, porque las partes -los verdaderos protagonistas-no son los mismos antes, durante y después de la mediación? 7 .

7 C. Gotheil, «La mediación y la salud del tejido social». 


\section{LA PARTICIPACIÓN RESPONSABLE}

¿Cómo participar efectivamente en la búsqueda de consensos, aún cuando sabemos que las situaciones conflictivas generan siempre procesos precarios? Convengamos en que no es lo mismo participar que estar presente en la mediación. ¿Cómo hacer para dar a conocer sus posiciones y persuadir al otro que las acepte, si no puede expresarse? Como seres autónomos no solamente tienen derecho a ser oídos sino también a escuchar lo que el otro tenga para decir. Para lograr esta competencia cívica, los ciudadanos precisan oportunidades para expresar sus propios puntos de vista, para aprender de los otros, para entablar discusiones. Sin esas posibilidades se transforman en ciudadanos silenciosos, súbditos perfectos de gobiernos autoritarios.

Para alcanzar esa participación efectiva y responsable hay que pararse en la realidad cotidiana para, desde allí, construir o descubrir las posibilidades entre las que se elegirán las más adecuadas para cada uno. Y para ello hay que conocer muy bien esa realidad desde la que se parte. Sólo así podrán imaginarse alternativas viables. La falta de información empobrece las opciones Se trata simplemente de ser realistas, lo que no implica atenerse solamente a los hechos como si hubiera una única salida, sino tratar de ampliar lo real desde lo que es y hacia lo posible. Hacerse cargo de esa realidad y no caer en utopías, aún con una base normativa. A su vez desde ella se podrán justificar las elecciones. Muchas veces se toman decisiones desde posiciones equivocadas y dogmáticas. Sólo la disposición a dialogar permite superar ese dogmatismo y el egoísmo. Se trata de estar capacitados para juzgar y tomar decisiones posibles, razonables, prudentes. Y esta capacidad no es congénita, por el contrario, es parte de la educación moral y ciudadana.

Aún cuando reconozcamos entidad suficiente al conflicto como para dirimirlo a través de la vía judicial tradicional, en la familia o la escuela, en el barrio o la comunidad no todos están en condiciones de llevar su litigio a tribunales. No entrenados en el lenguaje jurídico, requieren de la asistencia técnica para acceder a un sistema que se les muestra incomprensible y complejo en cuanto a vocabulario, procedimientos e instituciones. Son barreras de comunicación que se dan entre los usuarios del sistema y los operadores jurídicos, y que expresan ese mito o ficción del «Derecho conocido por todos», como han señalado los juristas de la teoría crítica. Es lo que Cárcova llama «opacidad del Derecho», que desemboca en un efectivo desconocimiento, con matices que van desde la ignorancia por situaciones de marginalidad o exclusión, al desconocimiento parcial del ordenamiento jurídico complejo, que puede llegar a afectar incluso a ciertos operadores jurídicos. Son muchas las razones que explican este fenómeno: la complejidad técnica de los institutos, los mecanismos de manipulación y ocultamiento, los contenidos «ficcionales» del Derecho, y 
la variedad y cruce de pautas culturales que constituyen visiones fragmentadas $^{8}$. Por ahora, nos interesa remarcar que, en ese contexto, a los ciudadanos se les debería facilitar no solamente el acceso a la información legal sino también la comprensión cabal de sus derechos y deberes, como así también las posibles vías legales para hacerlos valer, y los modos más apropiados de resolver sus conflictos.

Si aceptamos que no todos tienen la capacidad de comprender y apropiarse del discurso de los derechos, deben establecerse mecanismos compensatorios para esos sectores de menores recursos, socialmente vulnerables, por su misma condición de marginalidad que afecta cada vez a más gente. Entre ellos podríamos mencionar no solamente las fórmulas alternativas de justicia estatal como la mediación y/o conciliación, el arbitraje, instancias conciliatorias prejudiciales, sino también la asistencia legal vecinal gratuita, consultorios jurídicos, etc. Se trata simplemente de acercar a los ciudadanos al sistema de Justicia. Por otra parte, por qué no pensar también en posibles beneficios futuros. Si acostumbramos, a través de una decidida acción educativa, a los niños y jóvenes al diálogo, aún confrontativo, para zanjar diferencias al menos en su etapa inicial, el beneficio para estos jóvenes se hará extensivo el día de mañana, a través de ellos en su rol de ciudadanos, a la sociedad entera, con lo que habremos contribuido eficazmente a la pregonada cultura de la paz.

Junto a estos mecanismos, también cabrá instituir prácticas de participación efectiva, que actualicen el sentido de la vida democrática, y que enseñen a ser y ejercer la ciudadanía. Ya dijimos que no es algo naturalmente dado, sino que a ser ciudadano se aprende. Si adoptamos una participación cooperativa responsable, nos acostumbraremos a dirimir nuestros problemas inicialmente entre nosotros, los directamente afectados, o al menos a acordar cómo deben ser resueltos, lo que no es responsabilidad exclusiva de los operadores del Derecho. Esta es otra forma de acercar a los ciudadanos al sistema de Justicia ${ }^{9}$.

$\mathrm{Si}$ aspiramos a la profundización del estilo de vida democrático, apoyado en criterios de autonomía, de participación ciudadana y de paz, será conveniente garantizar las mismas y efectivas oportunidades de participar para todos los miembros de nuestra comunidad. La construcción de las diversas formas de vida y de una ciudadanía reflexiva requiere de instituciones que fomenten el diálogo, y promuevan consensos. Con moderado optimismo creemos que a través de esos espacios de gestión participativa puede revertirse la desconfianza en la imparcialidad y credibilidad de las instituciones públicas y en la capacidad del Estado para instaurar instancias efectivas de participación.

8 Cf. C. Carcova, La opacidad del derecho. I Parte.

9 Cf. Tarrio-Benin Chirico, A seis años del comienzo de la aplicación práctica de la mediación comunitaria. p. 1256. 
Si los ciudadanos han de ser competentes para resolver sus conflictos, ¿Todos están igualmente calificados para participar en los procesos de toma de decisiones? ¿no precisan instituciones sociales y políticas que les transmitan esa capacidad? Ella constituye un requisito fundamental para que la participación sea efectiva, lo que no implica que aún así no se puedan cometer errores. Por eso es importante la educación. La educación cívica no sólo requiere una escolarización formal, sino que exige también la discusión, la deliberación, el debate y las controversias públicas, a partir de la disponibilidad efectiva de informaciones fiables y suficientes. Si las instituciones encargadas de promover la educación cívica dejan de lado la dimensión comunicativa de la ciudadanía, difícilmente serán efectivas. Quizás ya no sean adecuadas y haya que renovarlas. Insistimos en la necesidad de reorganizar nuestras instituciones en el marco de lo que podríamos llamar democracia dialogante. Formidable desafío para el siglo XXI.

La participación ciudadana se construye, a través de la multiplicación de los espacios públicos y con el involucramiento de los sujetos en tanto gestores sociales de los conflictos. Es necesario habituar a los ciudadanos para resolver sus propios problemas a través del diálogo. No caer en la pacificación de las demandas sociales a costa de formalidades reducidas a políticas asistenciales y/o tutelares, cuestionables en tanto constituyen simulacros de solución. No proponemos una visión de la sociedad completamente cooperativa o conformista, sino pasar de una mera preocupación por los derechos formales a procurar identificar cómo pueden generarse más y mejores condiciones de autonomía a los ciudadanos.

\section{LA MEDIACIÓN ENTRE NOSOTROS}

Como suelen sostener los juristas comprometidos con estas vías alternativas, podría establecerse una relación directa entre la calidad democrática de una sociedad y la cantidad de herramientas que ella posee para resolver sus conflictos. Lógicamente, es más democrática en la medida en que privilegie una mayor participación en la toma de decisiones por parte de los ciudadanos, y concretamente en el uso de procedimientos más pacíficọs para resolver los conflictos. En ese sentido, si recurrimos a la mediación en busca de una solución no se delega la toma de decisiones, como en el caso del juez, sino que se la asume plenamente, privilegiando las necesidades, preocupaciones e intereses de la gente involucrada en el conflicto y buscando restablecer la paz.

En un contexto agudamente crítico, como puede sin duda calificarse la situación actual de Argentina, en el que los gobiernos nacional y provinciales toman decisiones frecuentemente condicionados por grupos de intereses nacionales o extranjeros -capaces de mostrar sus pretensiones a los centros de 
poder político-, y donde, sin embargo, grandes sectores de la ciudadanía, marginados socialmente, no poseen fuerza que canalice de forma sostenida sus demandas, ni pueden movilizarse políticamente de modo tal que se los tenga en cuenta en las decisiones oficiales, quizás resulte una fantasía hablar de esas relaciones solidarias y comprometidas que fundamentan la mediación.

Para ciertos sectores sociales con poder, puede ser una realidad hablar de autogobierno. Pero en el caso de los marginados, que sólo son tenidos en cuenta por razones de seguridad pública, al momento de cometer un delito, ¿cómo podemos hablar allí de participación, si no garantizamos ciertas condiciones mínimas exigibles para que la misma sea efectiva? Dadas las características de nuestra decadencia cívica actual, es ilusorio pensar en medidas aisladas. En muchos casos hay que vencer el hambre diariamente, por lo tanto antes que nada debería lograrse un mínimo desarrollo económico que asegure localmente ciertas condiciones de vida aceptables que hagan posible la convivencia social. Necesitamos la reconstitución de la sociedad civil, que apunte a paliar la fragmentación producida por la simultánea exclusión de los de abajo y los de arriba, aunque de modos muy diferentes..

El orden público, en cuanto límite del ejercicio de los derechos humanos, podría ser entendido como el conjunto de condiciones organizativas y de funcionamiento de la sociedad que garantizan un desarrollo ordenado y pacífico de los respectivos derechos ciudadanos. Se requiere una concepción flexible del mismo, abierta y dinámica, y no simplista como un orden externo o la tranquilidad en calles y plazas. En las dos últimas décadas en nuestro país se han erosionado los mecanismos institucionales democráticos y dilapidado las posibilidades de expandir las capacidades de una efectiva acción estatal para mantener la paz social. Fracasaron diversos mecanismos de acción pública, tanto estatales como no estatales, que pretendían contrarrestar los efectos desintegradores e inequitativos que el mismo desarrollo capitalista había provocado. Se minimizaron los procesos institucionales con el consiguiente debilitamiento de la participación ciudadana y las capacidades de gestión pública. Vivimos una época de desanclaje social, en el que las relaciones sociales se encierran en micro-contextos locales de interacción, y se reestructuran en indefinidos intervalos espacio-temporales. A diario se producen múltiples y diversas manifestaciones acotadas que van desde cortes de calles y rutas, escraches, ocupaciones, marchas y asambleas, por parte de desocupados, piqueteros, ahorristas, trabajadores, etc.

En este contexto de fragmentación social planteamos la necesidad de resignificación del rol del ciudadano, a través de diversas formas de cooperación y aprendizaje, de su capacidad de articulación con el entorno, de su compromiso con los valores dominantes, de su posibilidad de ejercer el liderazgo decisional tanto en el ámbito público como privado. Es decir, entender que la 
dinámica específica de la ciudadanía juega un papel determinante en la capacidad de la sociedad para desarrollar su propio proyecto. Y cualquier política local que apunte en este sentido estará destinada a fracasar si no encuentra las bases colectivas sobre las que apoyarse. Para ello se necesita partir de relaciones solidarias y comprometidas.

La mediación puede ayudar aún no solamente a manejar los conflictos sino también a prevenirlos, e incluso evitar que su permanencia pueda desembocar en situaciones de violencia. Ante la difícil situación en que se encuentran nuestras instituciones, implementar acciones y programas integrales que tiendan a cambiar y mejorar la calidad de vida de los ciudadanos, es una necesidad urgente que nos debe convocar a todos. En situaciones críticas bien podría pensarse en la mediación como uno de los recursos posibles para el tratamiento y prevención de la violencia, aún teniendo en cuenta las limitaciones de esta práctica en contextos de desinformación o de desequilibrio de poder entre las partes en conflicto.

\section{UN CIUDADANO RESPONSABLE}

La coexistencia o convivencia no es nada fácil. Implica reglas, acuerdos, pactos implícitos o explícitos, costumbres y hábitos, pero también diferencias, broncas, peleas, enfrentamientos. El conflicto parece endémico en cualquier grupo. Podríamos recordar la «sociabilidad insociable» a que aludió Kant, o la democracia conflictiva que sostiene Ranciére, para actualizarnos en nuestra cita. Y debemos, entonces, cotidianamente dedicar esfuerzo, tiempo, y a veces también dinero, para resolverlos, para armonizar voluntades, hacer concesiones, o también enojarnos, marcar límites, o buscar las vías para imponer nuestra voluntad. Todo ello en muchas ocasiones se puede hacer en un clima pacífico, de respeto hacia los demás, y con mayor o menor grado de participación, compromiso y responsabilidad, según sea el caso de que se trate ${ }^{10}$.

Ante cada conflicto podemos plantearnos cuáles son los intereses efectivamente merecedores de tutela judicial. Cuáles, de los problemas que podamos tener en la familia, escuela, barrio, comunidad o municipio, requieren necesariamente para ser resueltos la concurrencia a los Tribunales.Cuántos deberían llegar allí y no llegan por desinformación o por falta de recursos. Cuántos llegan y no satisfacen a ninguna de las partes porque la solución, más allá de ser ajustada a Derecho, conlleva un agravamiento del conflicto a nivel de las relaciones humanas, o un resultado tan oneroso que se transforma en un obstáculo mayor ${ }^{11}$.

10 Cf. M. Spagnolo de Godoy, El fortalecimiento de la sociedad civil y la mediación. p.26.

11 Cf. N. López Faura - N. Sacoski, Mediación comunitaria. p. 1195. 
Ahora bien, la práctica nos muestra que hay muchos conflictos humanos que no necesariamente deben resolverse a través del proceso judicial: ni todo judiciable ni todo mediable. Por su misma naturaleza, la mediación no puede ser un método compulsivo, aún cuando por ahí pueda aparecer cierta obligatoriedad en algunas instancias. Pero apuntar a la voluntariedad tampoco implica que el Estado no deba preocuparse por la solución de los conflictos sociales, sino todo lo contrario, que debe buscar la más adecuada.

De hecho nuestro Estado ha reconocido el valor de la mediación, en tanto se ha plasmado en un texto legal (Ley 24.573), que la impone como paso obligatorio previo al juicio respecto de algunas cuestiones. A nivel provincial, y como dijimos más arriba, la Suprema Corte ha establecido la mediación obligatoria específica en el fuero de familia. Se multiplican programas municipales, barriales y vecinales de mediación comunitaria. Curiosamente, los propios abogados, que conocen mejor que nadie el desgaste de los tediosos litigios, son quienes más se resisten a la mediación. Quizás logre imponerse entre nosotros, pero no será por un mero voluntarismo de sus promotores, ni por la obligatoriedad legal, sino porque sus resultados sean efectivos en cuanto a la morigeración, resolución, autocomposición e incluso prevención de las situaciones conflictivas.

Estas formas alternativas de resolver los conflictos requieren de una participación activa y responsable. El reconocimiento de la autonomía de cada uno, la tolerancia, el respeto, la búsqueda de consenso para la solución, surgen como valores actualizados para convalidar la existencia misma de la sociedad, por cuanto rescata al ciudadano en su participación social responsable. Por eso, bienvenidas sean estas nuevas formas que fortalecen el diálogo para la solución del conflicto, sin necesidad de sobrecargar el sistema judicial. Aún cuando ello no significa desplazar otras formas de resolver controversias, sino por el contrario, junto a ellas constituirse en una opción más de los modos que el afectado tiene a su alcance.

Nuestra propuesta supone partir de una redefinición del espacio público, como un lugar donde no solamente se toman decisiones políticas fundamentales para la vida de los ciudadanos, sino donde también se desarrollan argumentaciones para tender puentes entre las distintas concepciones-de los individuos, como el lugar donde se juegan esas opciones En medio de una profunda modificación de las reglas del juego político, con una decadencia de la vida civil, monopolizada por instancias estatales, hablamos de rediseñar ese espacio más abierto, amplio y flexible, con múltiples focos de poder, y donde los equilibrios se consiguen a través de acuerdos, negociaciones, transacciones. Se trata, pues, de reinventar el espacio civil. 


\section{HACIA UN CAMBIO INSTITUCIONAL}

Para contribuir a plasmar una nueva forma política de organización social, entre otras medidas, sería conveniente la implementación de políticas sociales en red que apunten a la solución de conflictos a través de la participación de los mismos afectados. Esto permitiría acompañar a las partes en la contención del conflicto según las diversas etapas en que lo transitan. Es decir, que en lugar de limitar la mediación a una etapa inicial o previa al juicio, ella pueda ofrecerse en cualquier momento del circuito conflictivo. En este sentido, más que de una vía o proceso alternativo quizás podría hablarse de la mediación como herramienta que permite reconducir los circuitos de la comunicación. En vistas de contener el conflicto y solucionar las diversas disputas que pueden ir surgiendo, que sea posible recurrir a ella como una posibilidad más que se le brinda a los ciudadanos.

Nuestra propuesta, en un contexto de flexibilización de los procesos resolutivos en diversos ámbitos, supone cierta heterogeneidad organizacional, a la vez que requiere de participantes más reflexivos e informados. Los esfuerzos en la resolución de problemas deberían ser generados en el contexto mismo de aplicación y no proyectados primero en una instancia superior y aplicados en un momento posterior y por un grupo diferente, como ocurre en el ámbito de la justicia tradicional. La solución podrá comprender componentes teóricos y empíricos, por lo cual deberán preverse asignación de partidas específicas. Los resultados han de ser paralelos al proceso de su producción, y no comunicados posteriormente por determinados canales institucionales, como en el caso de las sentencias. Esto supone mucho dinamismo por parte de las instituciones. $\mathrm{Si}$ el circuito resulta exitoso, los patrones de organización y comunicación persistirán como una matriz para nuevas redes, de lo contrario se harán los ajustes necesarios. Sin duda, representa todo un desafío cómo gestionarlas, especialmente si pretendemos escaparnos de una rigidez normativa.

Las instituciones son las reglas de juego formales e informales que pautan la interacción entre los individuos y las organizaciones. La presencia de una sociedad civil articulada, con «densidad institucional» y con una intensa interacción social, es siempre un símbolo de mayor capacidad para el desarro1lo. Los intereses particulares de los agentes individuales tienden a adecuarse a los intereses colectivos. Necesitan un ambiente institucional y organizacional que respalde y oriente sus esfuerzos, sus energías, y encuadre sus actuaciones. Por ello remarcamos la necesidad de recurrir a políticas que fomenten la participación ciudadana en el proceso de toma de decisiones, debiendo adecuar el interés particular con el colectivo. Se necesita promover su capacidad decisional y organizativa. Creer en la capacidad convocante y aglutinadora de las actividades sociales y políticas. Todo ello no puede darse solamente en las institu- 
ciones educativas formalmente establecida. Requiere además otras herramientas, como las redes de confianza alternativas a las redes jerárquicas y de mercado. Ello permitirá oponer a la anomia el significado, a la indiferencia el compromiso, al riesgo e inestabilidad la búsqueda de la paz.

La paz no está reñida con la justicia, al contrario. Si buscamos solucionar los conflictos, vía pacífica, tenemos que garantizar que los acuerdos sean justos, de lo contrario, no son soluciones. Ante la aparente contradicción entre la unicidad y la universalidad del Derecho y la multitud de prácticas microsociales, locales, entre las que se puede insertar la mediación, que llevan a pensar que se está propiciando una fragmentación y privatización de las funciones públicas, proponemos una nueva relación de las vías alternativas con el Derecho. Bien entendidas, estas vías deben constituir opciones dentro de un sistema para resolver los conflictos sin necesidad de apelar al procedimiento judicial, lo que no implica decir «sin justicia». Esto supone que el proceso de mediación no se desarrolle encorsetado exclusivamente según lo establece la norma jurídica respectiva, como si fuera el único parámetro que debería contemplar la posible solución, sino en todo caso como un criterio más, al que pueden y deben agregarse otras consideraciones que para las partes son tanto o más importantes que el contenido de esa norma. También los intereses, posiciones, sentimientos, creencias, motivaciones, etc., junto a la norma confluyen en la autocomposición y solución del conflicto.

Es un falso dilema el de la mediación o la vía judicial tradicional. Aceptarlo implicaría, o bien una concepción muy restringida de esta última, en relación con el servicio de justicia que ella debe necesariamente prestar, o bien una restricción de la mediación a ser un servicio de segunda mano, para las clases menos pudientes y usada como política compensatoria, más bien de caridad que de calidad. Por cierto, la mediación tiene limitaciones, tanto desde el punto de vista del tipo de conflictos como de las efectivas posibilidades de las partes en participar con libertad y creatividad en la búsqueda de sus propias soluciones. Pero, sin duda, se trata de todo un desafío que, en aras de la paz social, persigue una forma de justicia posible y cercana a las partes. ¿Acaso no vale la pena?

Somos ciudadanos autónomos en un contexto democrático. Y la forma de ejercer la ciudadanía es a través de la participación y la solidaridad, en tanto mostramos un interés activo y no meramente declamativo por los demás. Lo podemos hacer a través de una serie de actividades cotidianas que van tejiendo ese nuestro lazo de pertenencia. No requiere que tengamos que buscar siempre un mediador profesional, aún cuando a veces pueda ser más beneficioso. Apuntamos a un cambio más profundo, a una cultura de la paz y de la solidaridad. Después de todo, la ansiada paz social no significa inmovilidad de los ciudadanos, sino convergencia de energías en una dirección consentida y concertada. 
Quizás pueda empezarse simplemente a través de una preocupación real por problemas de otros, aunque no nos afecten directamente. $\mathrm{Y}$ actuar consecuentemente.

\section{BIBLIOGRAFIA}

CARCOVA, C. La opacidad del derecho. Madrid: Trotta, 1998..

CUETO RUA, J.C. «El proceso de masificación y la resolución judicial de los conflictos», Diario La Ley, Buenos Aires, 19/07/00.

DWORKIN, R. Los derechos en serio. Barcelona: Planeta, 1993.

DWORKIN, R. La comunidad liberal. Colombia: Siglo del hombre, 1996.

GOTHEIL, C. «La mediación y la salud del tejido social», en GOTTHEILSCHIFFRIN, Mediación: una transformación en la cultura. Buenos Aires: Paidós, 1996, pp. 215-225.

HABERMAS, J. Facticidad y validez. Madrid: Trotta, 1998.

HABERMAS, J. Conciencia moral y acción comunicativa. Barcelona: Península, 1991.

HABERMAS, J. La necesidad de revisión de la izquierda. Madrid: Tecnos, 1991.

LOPEZ FAURA, N. - SACOSKI, N. «Mediación comunitaria», en La ley, Buenos Aires, 1997, t. E, p.1195.

RUBIO CARRACEDO, J: Educación moral, postmodernidad y democracia. Madrid: Trotta, 1996.

SPAGNOLO de GODOY, M. «El fortalecimiento de la sociedad civil y la mediación», La ley, Suplemento de resolución de conflictos (RC). Buenos Aires, 07/07/00.

TARRIO-BENIN CHIRICO. «A seis años del comienzo de la aplicación práctica de la mediación comunitaria», La ley, Buenos Aires, 1997, t. B, p. 1256. 